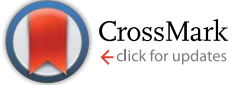

Cite this: RSC Adv., 2016, 6, 61599

Received 30th May 2016

Accepted 13th June 2016

DOI: $10.1039 / \mathrm{c} 6 \mathrm{ra13976k}$

www.rsc.org/advances

\section{Protein/peptide secondary structural mimics: design, characterization, and modulation of protein-protein interactions}

\author{
Zhipeng A. Wang, ${ }^{\text {ac }}$ Xiaozhe Z. Ding, ${ }^{\text {bd }}$ Chang-Lin Tian ${ }^{\text {a }}$ and Ji-Shen Zheng ${ }^{\text {*a }}$
}

Protein-protein interactions (PPIs) play a critical role in many essential biological processes, and numerous diseases result from malfunctioning PPIs. The modulation of undesirable PPIs via synthetic chemical molecules has long been considered of medical importance, but still remains challenging. Thanks to the development of synthetic chemistry, chemists can synthesize protein/peptide secondary structure mimics to modulate the specific PPIs. This review discusses general aspects of novel artificial peptide secondary structure mimics for the modulation of PPIs, their therapeutic applications and future prospects.

\section{Introduction}

Biological systems are highly complicated and regulated by sophisticated protein-protein interactions (PPIs). ${ }^{1}$ Almost all important biological processes, such as cellular signaling cascades or the infection of viruses, are closely related to PPIs. ${ }^{2,3}$ The malfunction of PPIs may be the cause of notorious diseases. ${ }^{4}$ Potent small molecule therapeutics have been developed for targeting PPIs in recent decades. ${ }^{5}$ However, the disruption of PPIs by small molecule binders continues to be difficult to achieve, ${ }^{6-8}$ because these interactions always involve relatively large binding areas, ${ }^{\mathbf{9 , 1 0}}$ i.e., the interface area between a protein signaling molecule and its receptor can range to thousands of $\AA^{2}$ (Fig. 1). ${ }^{11,12}$

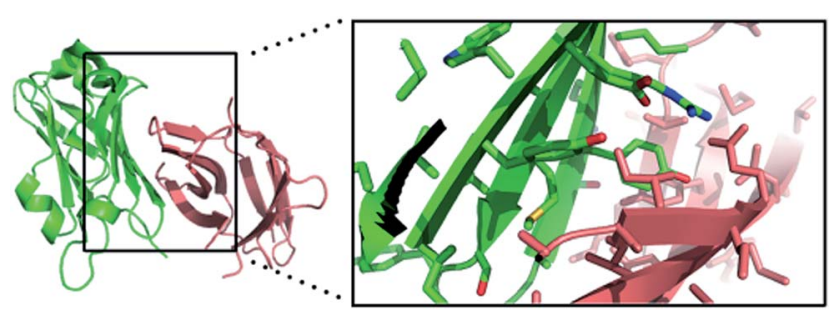

Fig. 1 The protein-protein interaction between human programmed death-1 PD-1 and its ligand PD-L1 with an interaction area of $1970 \AA^{2}{ }^{16}$ PDB ID: 4ZQK.

${ }^{a}$ School of Life Sciences, University of Science and Technology of China, Hefei 230026, China.E-mail: jszheng@hmfl.cas.cn

${ }^{b}$ School of Life Sciences, Tsinghua University, Beijing 100084, China

'Department of Chemistry, Texas A\&M University, College Station, TX, 77840, USA

${ }^{d}$ Department of Bioengineering, California Institute of Technology, Pasadena, California 91125, USA
With the increasing number of protein structure-activity relationship studies, we have gradually gained a better understanding of PPIs. The binding affinity between two proteins de facto comes from several key residues named "hotspot" or "anchor" residues, ${ }^{13}$ and the 20 natural amino acids have different contributions to these vital sites. ${ }^{14}$ Although these localized secondary motifs, known as "epitopes",15 are necessary for recognition, they may simply provide a scaffold to support these hotspots and mediate the interactions between two huge proteins. Thus, an alternative strategy is to generate artificially designed molecules to provide a similar scaffold to support the hotspots.

Native proteins can theoritically be directly used to inhibit PPIs. However, typical half-lives of proteins in living cells are just hours (with a mean half-life of $43 \mathrm{~min}$ ).${ }^{17}$ Moreover, using entire proteins directly as pharmaceuticals requires suitable potency and pharmacokinetic properties. ${ }^{18}$ But to date our ability to produce homogeneous proteins, especially those with posttranslational modifications, have been limited. ${ }^{19-22}$ Examples of monoclonal antibodies performing as antitumor drugs do exist, such as Bevacizumab, ${ }^{23}$ Nivolumab and Ipilimumab. ${ }^{24}$ However, the immune effects and safety profile over the long term are still concerns. Truncated proteins, or simply peptides with protein secondary structures, could provide potential solutions. Based on this concept, rational design based on X-ray crystallography and theoretical calculations, ${ }^{25}$ and random peptide screening such as phage display ${ }^{26}$ are combined in search of the minimal or simplified peptide segment that is required. ${ }^{27}$ However, these separated peptides tend to act differently compared with their behaviour in whole proteins, because the enthalpy change of secondary interactions in a limited region might not be enough to compensate for the entropy loss during the folding process. ${ }^{28}$

To retain the shape of the $\alpha$-helix, some additional covalent bonds are needed. One practical strategy to stabilize $\alpha$-helix 
peptides was introduced by Verdine and collaborators, ${ }^{29}$ and a large variety of chemical bonds and structures have subsequently been utilized to achieve this goal in these conformationally locked peptides, which are descriptively named stapled peptides. With staples using "native" disulfide bonds, ${ }^{\mathbf{3 0}}$ allhydrocarbon cross-links, ${ }^{31}$ hydrocarbon chains, ${ }^{32}$ ring closing metathesis reaction (RCM) linkage, ${ }^{33} \mathrm{Cu}(\mathrm{I})$ catalyzed azide/ alkyne cycloaddition (CuAAC) based linkage, ${ }^{34}$ or diaminodiacid building block linkage, ${ }^{35,36}$ such peptides show bioactivity comparable with the native binding moiety ${ }^{37}$ even under in vivo conditions. ${ }^{38}$ This method largely equips us with the capability to handle helices for further analysis, stimulation and inhibition, ${ }^{39,40}$ and also provides a powerful weapon for current drug design. ${ }^{41}$

However, it is still difficult to stabilize other secondary structures (strands, turns, loops) besides $\alpha$-helices. Those bioactive conformations mediate most biological processes that define growth, ageing, disease and death. For example, isolated $\beta$-strands have a high tendency for aggregation, which is the major factor causing neurodegenerative diseases such as Alzheimer's disease. ${ }^{\mathbf{4 2}}$ Additionally, the delivery of both proteins and peptides can be problematic unless specially facilitated, ${ }^{\mathbf{4 3}}$ especially when treated as oral drugs. ${ }^{44}$ To summarize, people have started to look for other alternatives with high comparability and better performance compared with the skeletons coming from native proteins to overcome these challenges.

In this review, we will focus on summarizing the existing molecular designs of protein and peptide secondary structure mimics. "Peptide secondary structure mimics" will be used to indicate a more specific structural mimicking purpose, instead of the term "peptidomimetics". These designs are generally targeting a structural similarity to the $\alpha$-helix, $\beta$-strand/ $\beta$-sheet/ $\beta$-hairpin, ${ }^{45}$ and various turns based on numerous physical chemistry principles (Fig. 2). Some of these diverse and sophisticated structures have already been used as PPI inhibitors for a number of therapeutic purposes. Furthermore, mimetics have also demonstrated the importance of chemical design in the process of modifying and changing the nature of proteins and peptides. We will divide them into three main categories based on their chemical structure designs. The

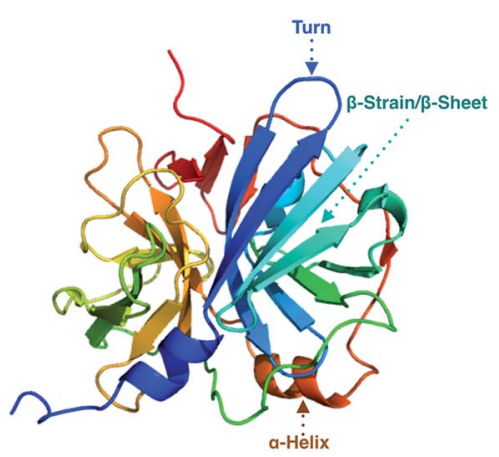

Fig. 2 Three secondary structures of Tobacco Etch Virus (TEV) protease C151A mutant. PDB ID: 1Q31. $\alpha$-Helix range from E24-T29: orange; $\beta$-turn range from G53-V66: dark blue; $\beta$-sheets range from N185-N192: light blue. synthesis processes, structural analysis, and some applications will also be introduced.

\section{2. $\alpha$-Peptides with non-native amino acid units to modulate protein-protein interactions}

Non-native amino acid containing $\alpha$-peptides have been widely used for the modulation of protein-protein interactions. This kind of secondary structure mimic is usually generated by the introduction of non-native amino acid units into native peptides/proteins by peptide/protein total synthesis, ${ }^{46-49}$ semisynthesis, ${ }^{50-53}$ or noncanonical amino acid incorporation technique (ncAA) ${ }^{54,55}$ combined with bioorthogonal reactions..$^{56,57}$ Therefore, the development of new synthetic strategies is always of potential advantage for the preparation of novel structures. ${ }^{58-61}$

\subsection{Non-native amino acid units mimicking turn structures}

The introduction of non-peptidic units into a native peptide chain is mostly applied as turn-mimics. Turns reverse the direction of peptide helices and strands to form compact structures. They serve as epitopes in peptides and proteins. Both cyclic structures and acyclic structures have been exploited to mimic turns, with conformational constraint as the key requirement. ${ }^{62}$

2.1.1 Cyclic structure units. Cyclic units have been utilized to mimic turn structures since the $1980 \mathrm{~s}^{63}{ }^{6}$ Kelly's group $^{64}$ reported the nucleation of anti-parallel $\beta$-sheets in water by harnessing a dibenzofuran unit, which formed a turn structure by folding against the sheet and generating a hydrophobic cluster with the side chains of the neighbouring residues (Fig. 3a). Nowick's group ${ }^{65}$ developed a more simplified approach to mimic a hairpin turn structure in chloroform, with a hybrid oligomer (oligourea and azapeptide) containing peptide (Fig. 3b). The turn-like structures generated in this way contained two intramolecular hydrogen bonds. Additionally,

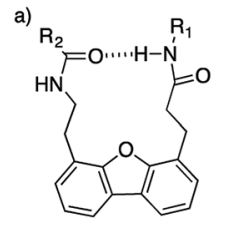

d)

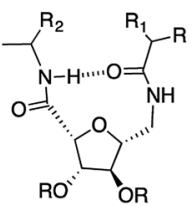

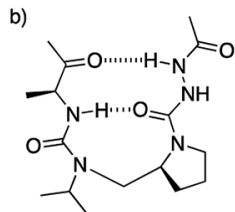

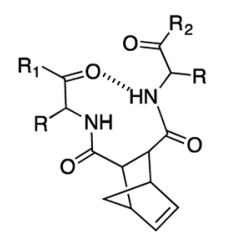

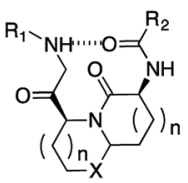

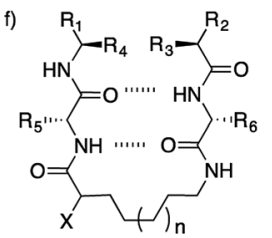

Fig. 3 Cyclic structure units serving as turn mimics. (a) Dibenzofuran derivative, (b) oligourea and azapeptide derivative, (c) azacycloalkane and azabicycloalkane amino acid derivatives ( $n=0,1$ or $2, \mathrm{X}=\mathrm{C}$ or $\mathrm{S}$ ), (d) furanoid sugar amino acid derivative, (e) bicyclo[2.2.1]heptane derivatives, (f) simple alkane chain derivatives. 
Lubell's group ${ }^{66}$ designed, synthesized, and analysed a series of azacycloalkane and azabicycloalkane amino acid derivatives as constrained peptide analogues (Fig. 3c) and their derivatives. ${ }^{67}$ In model peptide systems, they showed that these tools could be used to mimic the dihedral angles in the backbones of type II $\beta$ turn, type VI $\beta$-turn and $\gamma$-turn. The same group ${ }^{68}$ also applied several azacycloalkane containing turn mimics to the study of the structure-activity relationship in the interaction between the opioid receptor-like (ORL1) receptor and its peptide ligands. The result suggested two new antagonists, mimicking the central position of $i+1$ and $i+2$ of the typical Via $\beta$-turn, exhibited higher selectivity over $\mu$-and $\kappa$-opioid receptors (hMOR and hKOR).

Even sugar amino acids can be applied for the generation of turn structures. Grotenbreg ${ }^{69}$ et al. created an unusual reverse turn structure with a furanoid sugar containing amino acid, and this novel turn structure was used to replace the native turn unit in the antibiotic gramicidin S (Fig. 3d). Structural analysis showed the entire secondary structure was supported by the unexpected turn of the non-natural unit, which could improve the pharmaceutical properties of cyclic peptides as an antibacterial drug. ${ }^{70,71}$ It is noteworthy that some rationally designed external units might not form structures as expected. Ranganathan et $a l .{ }^{72}$ and Jones et al. ${ }^{73}$ designed bicyclo[2.2.1] heptane derivatives as proline structure mimics to provide nucleating turn mimics, separately (Fig. 3e). However, the crystal structure exhibited a different folding model for this group of oligomer. An increasing number of novel turn mimics are being developed with a more specific purpose of targeting, such as benzazepin-3-one or benzodiazepinone derivatives as a new group of $\beta$-turn ${ }^{74}$ or $\gamma$-turn mimics, ${ }^{75}$ respectively. More complicated motifs with turn structures as a $\beta$-hairpin motif have also been mimicked $^{76}$ and characterized. ${ }^{77}$

2.1.2 Acyclic structure units. Besides those cyclic units, simple alkane chains (such as long chain $\omega$-amino acids) have been used to replace those complex structures. This idea was first realized by the Nowick group, ${ }^{78}$ and the characterizations showed an expected turn structure (Fig. 3f). Furthermore, the Gellman group ${ }^{79}$ reported an acyclic $\beta$-turn mimic utilizing alkene structures that could mimic amide bonds in natural turns. The acyclic structure, trans-5-amino-3,4-dimethylpent-3enoate residue, could avoid the allylic strain in the transalkene moiety and promote the backbone to adopt $\beta$-turn and $\beta$ hairpin conformations. These acyclic turn mimics have theoretically fulfilled the purpose of mimic generation on the design level, and they were on the way to being widely applied to more specific PPI target inhibitions. ${ }^{80}$

\subsection{Non-native amino acid units used to mimic other localized structures}

Non-native structures can also be incorporated into peptides to endow peptides with certain natural or non-natural structures and properties. ${ }^{81,82}$ For example, non-natural units can mimic a cis peptide bond, which normally requires a proline in natural peptides. The ability to control the cis/trans geometry of peptide bonds is also important for the synthesis of turn mimics.

1,2,3-Triazoles, easily generated by Huisgen cycloaddition reactions, can be good peptide bond mimics. ${ }^{83}$ Methods have been developed for the synthesis of 1,2,3-triazoles using copper-catalyzed azide alkyne cycloaddition ${ }^{84}$ (CuAAC) ${ }^{85}$ or ruthenium-catalyzed azide alkyne cycloaddition ${ }^{86,87}$ (RuAAC). The products have similar structures and electronic properties to those of peptide bonds. Ghadiri's group ${ }^{88}$ used synthetic peptidomimetics of tetrapeptide Apicidin, a naturally existing inhibitor of histone deacetylase (HDAC), to study the inhibition potency of the molecules in different conformations. They synthesized mimics of Apicidin with triazoles mimicking different percentage combinations of cis/trans peptide bonds. The results showed that the peptidomimetic with 1,5-substituted triazole was bioactive, and could mimic a cis-transtrans-trans geometry (Fig. 4a and b), and this further supported that this cis-trans-trans-trans geometry was the bioactive conformation of Apicidin. Ghadiri's group also synthesized and analyzed 1,4-substituted triazole-based peptidomimetics as ligands for the somatostatin receptor (SSTR). ${ }^{89}$ In this study, the group used 1,4substituted 1,2,3-triazole to mimic trans-peptide bonds.

Amide bond isosteres have also been created as peptide mimics. Based on previous developments, Wipf and coworkers compared different trisubstituted (E)-alkene isosteres ${ }^{90}$ (Fig. 4c). They found that the trifluoromethylated derivative was the best combination of both the stereo effect with the electrostatic effect when mimicking the amide bond. Recently, an oxetanylamine fragment with non-hydrolysable property and a similar H-bond pattern was used to replace the amide bond (Fig. 4d). With the introduction of this structural fragment, oxetanyl peptides $^{\text {91 }}$ were developed as a novel peptidomimetic for potential pharmaceutical applications.

\section{Non-natural poly-amide based secondary structure mimics to modulate protein-protein interactions}

Considering that native proteins are all made up of 20 natural $\alpha$ amino acids, several mimics starting from the non-natural

a)

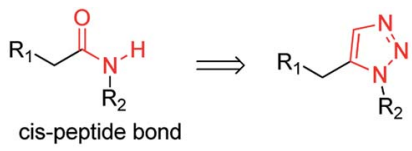

b)

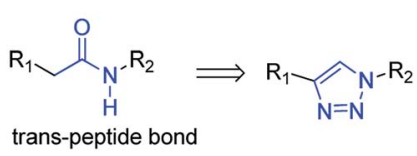

c)

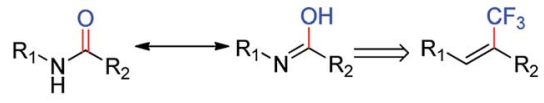

d)

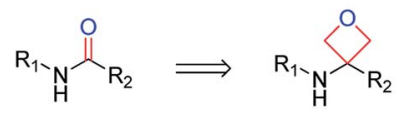

Fig. 4 Non-native amino acid units used to mimic other localized structures: (a) cis,trans-peptide bond, and (b) amide bond isosteres, (c) trifluoromethylated $(E)$-alkene isostere as a peptide bond mimic, (d) oxetanylamine structure as a peptide bond mimic. 
amino acid monomer level have been developed. These nonnatural units include $\beta$-amino acids, $\gamma$-amino acids, peptoids, etc. These polymers or oligomers with definite secondary structures are also referred to as foldamers. ${ }^{92}$ Herein, $\beta$-peptide and peptoid will be discussed due to their wide popularity. The reader is directed to previous reviews for discussion of $\gamma$ peptide, ${ }^{93,94} \delta$-peptide,${ }^{95} \varepsilon$-peptide, ${ }^{96}$ or peptides made from cyclic amino acids ( $\zeta-\xi$-peptides), ${ }^{97,98}$ or oligomers of diamine and dicarboxylic acid known as "retro-inverso peptides". ${ }^{\mathbf{9 9 , 1 0 0}}$

\section{1 $\beta$-Peptide \& its analogs}

$\beta$-Amino acids are similar to $\alpha$-amino acids in that they contain an $\mathrm{N}$-terminus amino group and a C-terminus carboxyl group. $\beta$-Peptides are composed of $\beta$-amino acids which can exist as $R$ or $S$ isomers at either the $\alpha$-carbon (C2) or the $\beta$-carbon (C3). The vast range of stereo- and regioisomers significantly expand the structural diversity of $\beta$-peptides (Fig. $5 \mathrm{a}$ ). The introduction of $\beta$-amino acids has been achieved for the synthesis of $\beta$ peptides that not only have potent activity to modulate proteinprotein interactions, but are also stable against proteolytic degradation. The applications of bioactive $\beta$-peptides include as receptor agonists, antimicrobial peptides, peptidase inhibitors and so on.

In their pioneering work, Seebach and coworkers ${ }^{\mathbf{1 0 1}}$ synthesized a series of small $\beta$-peptides (Fig. 5b), and a 2D-NMR structural study showed that these $\alpha$-peptide mimics could form a rather stable $3_{14}$-helix structure. In these patterns, each amino group from the $i$ th residue can hydrogen bond with the corresponding carboxyl groups from the $(i+2)$ th residue. Therefore, each helical cycle contains exactly three $\beta$-amino acid units. Gellman's group ${ }^{\mathbf{1 0 2}}$ extended these structures from linear $\beta$-amino acids to cyclo- $\beta$-amino acids. The incorporation of the two main chain carbon atoms into a certain alkyl-ring can increase the rigidity of the substrates. They first evaluated the

a)
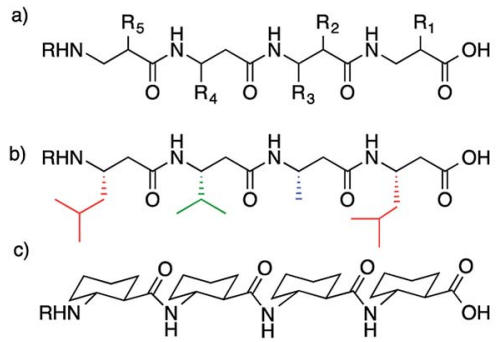

d)

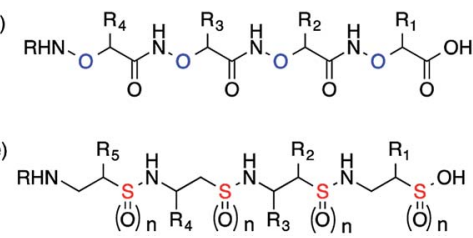

Fig. 5 Different types of $\beta$-peptide and its analogs. (a) Linear $\beta$ peptides with different possible side chain substitution groups, (b) an example of a $\beta 2$-peptide (ref. 92), (c) oligomers of trans-2-aminocyclohexanecarboxylic acid (trans-ACHC) as a cyclic $\beta$-peptide, (d) poly-( $\alpha$-aminoxy acids) as a $\beta$-peptide analog, (e) oligomer $\beta$-sulfinamides $(n=1)$ or $\beta$-sulfonamides $(n=2)$. molecular energies with the existence of different numbered rings via computational methods, and the configuration relationships on the rings were also considered. Then, several related oligomers with trans-2-aminocyclohexanecarboxylic acid (trans-ACHC) (Fig. 5c) were synthesized and NMR data showed that they adopt a highly stable helix structure. ${ }^{103}$

Considering the structural similarity, poly-( $\alpha$-aminoxy acids) as a $\beta$-peptide analog was developed by replacing one of the carbon atoms with an oxygen atom (Fig. 5d). ${ }^{\mathbf{1 0 4 , 1 0 5}}$ Yang and coworkers first synthesized the scaffolds, which exhibited an unexpected $i$ to $i+2$ hydrogen bond model to form an eight membered ring. ${ }^{106}$ This novel turn and helix structure geometry has not been observed for a normal $\beta$-peptide. Another thing worth mentioning is that the hybrids of these monomers could form completely different structures. Kunwar's group ${ }^{\mathbf{1 0 7}}$ designed and synthesized a hybrid of $\beta$-amino acids and $\alpha$ aminoxy acids, which produced a 12/10-helix as a novel folding motif. Currently, poly-( $\alpha$-aminoxy acids) has been applied as a chloride receptor to facilitate chloride anion transport across artificial liposomes, which may benefit the transportation in living cell membranes. ${ }^{108}$

Additionally, some other $\beta$-peptide derivatives have also been introduced for the purpose of $\alpha$-peptide secondary structure mimicking, with a large structural diversity. ${ }^{109}$ Sulfinamide and sulfonamide derivatives, for example, serve as the analogs of carboxamide intermediates due to the coordination numbers of sulphur atoms of three or four, as well as the potentially similar hydrogen-bonding model. Sulfinamides or sulfonamides can work as carboxyl group analogs especially when forming intermediates in typical nucleophilic addition reactions. $\beta$-Sulfinamide or $\beta$-sulfonamide oligomers are introduced as carboxylic peptide structural mimics, which significantly extended the structural diversity and flexibility of normal carbon based $\beta$-peptides (Fig. 5e). ${ }^{\mathbf{1 1 0}}$ These types of oligomers were prepared using the solid phase synthesis method ${ }^{111}$ and employed as potential inhibitors of HIV protease. ${ }^{112}$

One outstanding feature of $\beta$-peptide is its helix formation manner, which is similar to that of $\alpha$-peptides. Although normal $\beta$-peptides have a $3_{14}$ helical conformation through the $[(i)$ $\mathrm{NH} \cdots \mathrm{O}=\mathrm{C}(i+2)]$ H-bond (Fig. 6a), different substitution models might result in different $\mathrm{H}$-bonding structures even inside a single $\beta$-peptide. For example, $12 / 10 / 12$ is a term used to describe a group of $\beta$-peptides in which the $\mathrm{H}$ bonding models at both terminal residues are different from those in the middle (Fig. 6b shows the ring containing either 12 or 10 atoms). In contrast, $\gamma$-peptides (discussed in Part 3.2) are normally in a $2.6_{14}$ helix conformation (Fig. 6c).

Turn structures can also be mimicked in $\beta$-peptides by the introduction of a non-amino acid unit into a $\beta$-peptide sequence. The Gellman group made a nucleating turn mimic in $\beta$-peptides. ${ }^{113}$ They utilized a heterochiral nipecotic acid dimer turn to promote a hairpin structure in adjoining $\beta$-peptide strands. Seebach and coworkers took another approach to make turns in $\beta$-peptides. ${ }^{114}$ They utilized a $\beta$-dipeptide from the central ten-membered hydrogen-bonded turn of the 12/10/12 helix, and showed that $\beta$-peptides inserted with these two homochiral $\beta$-amino acids took on a similar conformation to 
a)

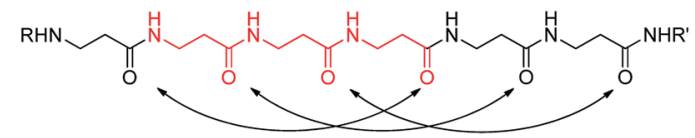

b)

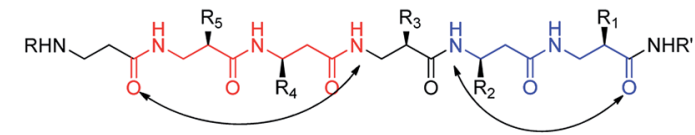

c)

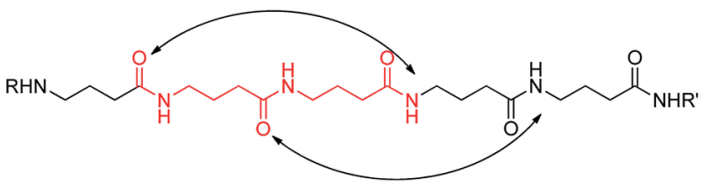

Fig. 6 Helix structures for $\beta$-peptides and $\gamma$-peptide. (a) Normal $\beta$ peptide helical plot, (b) special 12/10/12 helical plot, (c) $\gamma$-peptide helical plot.

that in the turn of that $12 / 10 / 12$ helix. The structural design, followed by characterization, are still the main tasks of $\beta$ peptide studies. However, rational design combined with computational prediction remains challenging for the purpose of helix mimicking, with limited achievements so far.

$\beta$-Peptides have been applied in several different medical fields. The Seebach group made use of a $\beta$-peptide with a 14helix structure for inhibition of the apolipoprotein-receptor interaction. ${ }^{115}$ Tests of antibacterial activity showed that some $\beta$ peptides even had micromolar $\mathrm{IC}_{50}$ values as well as high cell lysis activity. For example, three different $\beta$-peptides have been developed as potential inhibitors of cholesteryl oleate uptake, which could successfully fold into $3_{14}$-helices to exhibit an amphipathic character (Fig. $7 \mathrm{a}-\mathrm{c}$ ) with a range of $\mathrm{IC}_{50}$ values. On the other hand, these peptides with high cytotoxicity showed similar effects on both red blood cells and bacterial cells. To summarize, $\beta$-peptides with carefully optimized lengths and structures may be candidates for novel antibiotics. ${ }^{116}$

\subsection{Peptoids}

Peptoids are a class of artificial peptidomimetics with the side chains covalently linked to the nitrogen atom, rather than to the

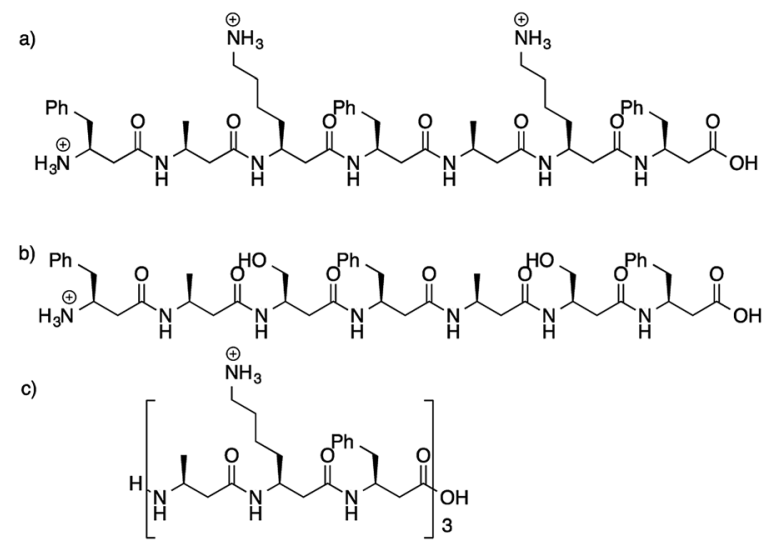

Fig. 7 Structural examples of $\beta$-peptides serving as cholesteryl oleate uptake inhibitors. $(\mathrm{a}-\mathrm{c})$ Three examples of $\beta$-peptides with different side chain substitution groups (ref. 115). $\alpha$-carbons. ${ }^{117} \beta$-Peptoids ( $N$-alkyl- $\beta$-alanines), with the $N$-substitution of $\beta$-peptides, have been reported as another type of backbone-modified peptide mimics (Fig. 8a and b), ${ }^{118}$ which also have applications in drug or gene delivery. ${ }^{119}$

Unlike natural peptides, no hydrogen bond donor exists in the backbone of peptoids, and the major forces which stabilize the secondary structures of peptoids are steric and electronic interactions. ${ }^{120} \mathrm{X}$-ray crystal structure analysis shows that this special group of peptoids can exhibit a similar structure to polyproline I peptide helix ${ }^{121}$ (Fig. 8c). Furthermore, Shin et al. reported peptoid macrocycles forming a reverse-turn conformation. ${ }^{122}$

Desired peptoids can be produced via solid phase synthesis with high convenience, low cost, and high efficiency. Additionally, any primary amine can be incorporated into a peptoid using a submonomer synthetic method. Therefore, we can extend the choice of side chains from natural amino acid side chains to theoretically any desired artificial group. ${ }^{123}$ The first preparation of peptoids by solid-phase synthesis was proposed by Zuckermann et al. in $1992 .{ }^{124}$ More recently, other methods for the solid phase synthesis of $\alpha$-peptoids and their derivatives have been developed. ${ }^{125}$ Typical strategies of polymer synthesis, such as living alternating copolymerization between carbon monoxide and $N$-alkylaziridines, can also be applied to peptoid synthesis. ${ }^{126}$ There are also established methods for the synthesis of $\beta$-peptoids. ${ }^{127}$

Because of their versatile natural properties and wellestablished synthetic methodologies, peptoids have been widely applied in drug design and fundamental biological research. Moreover, peptoids are resistant to proteolysis, which is a critical advantage over natural peptides for therapeutic applications. One of the earliest and most obvious applications of peptoids is to screen the binding partners of target proteins (especially receptors). Scientists at Chiron Corporation 127 first demonstrated this application by screening a combinatorial library of peptoids for ligands of the famous G-protein coupled receptors (GPCRs), which were well known as targets of many drugs. They synthesized a library of dimer or trimer peptoids with different substitution groups (Fig. 9a). Then, they screened the library in competitive radioligand-binding assays resulting in the discovery of some high-affinity ligands for GPCR. Several peptoids were selected for the $\alpha$-adrenergic acceptor (Fig. 9b)

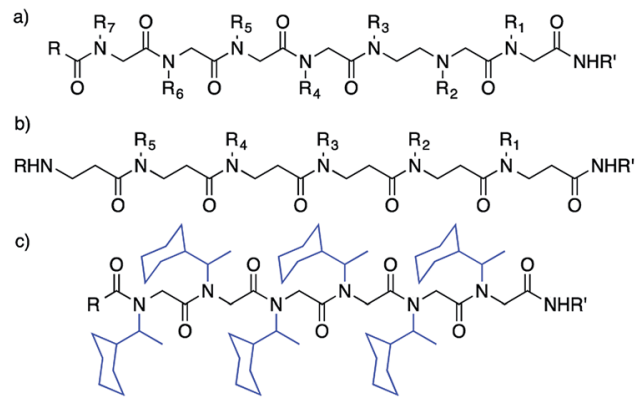

Fig. 8 Structure of $\alpha$-peptoid and $\beta$-peptoid compared with normal peptide. (a) $\alpha$-Peptoid (b) $\beta$-peptoid (c) $N$-(1-cyclohexylethyl)glycine oligomer as an example of $\beta$-peptoid (ref. 112). 
and for the $\mu$-specific opiate receptor (Fig. 9c) with binding constants of $5 \mathrm{nM}$ and $6 \mathrm{nM}$, respectively. Kodadek's group ${ }^{129}$ carried out a series of studies in an attempt to apply a similar strategy to screen for ligands for vascular endothelial growth factor receptor 2 (VEGFR2) with a cell-based, double-colored assay. Among the VEGFR2-binding peptoids, they found a candidate as a decent antagonist of VEGFR2 activity with a $K_{\mathrm{D}}$ value of around $20 \mathrm{nM}$. In another study, the same group ${ }^{\mathbf{1 3 0}}$ used a similar approach to identify antibodies that could be useful for diagnosis of diseases, and surprisingly they found two antibody IgGs as biomarker candidates for Alzheimer's disease. Additionally, Barron and coworkers used peptoids as synthetic lung surfactants or novel antimicrobial agents. They developed the novel concept of "ampetoids" (antimicrobial peptoid oligomers), and demonstrated that the ampetoids could have an analogous mechanism to those of AMPs in vitro. ${ }^{\mathbf{1 3 1}}$ In addition, they also exploited peptoids as good mimics of SP-C, a key part of the pulmonary surfactant system. ${ }^{\mathbf{1 3 2}}$

In spite of the progresses described above, it still remains challenging to design peptoids to mimic desired peptide structures, because of the difficulties in predicting the structure of the peptoids. Peptoids lack the regular hydrogen bonding that exists in natural protein secondary structures. ${ }^{133}$ Therefore, additional forces (such as steric or electronic interactions) are usually introduced into the peptoids to form secondary structure mimics, which makes the calculation of energies associated with different conformations particularly difficult. ${ }^{\mathbf{1 3 4}}$

\section{Non-amide polymer based secondary structure mimics to modulate protein-protein interactions}

It is much more challenging to make up protein-like scaffolds from non-amide oligomers/polymers. However, this group of mimics turned out to exhibit more tailorable structures, some of which have been successfully applied to bind with certain biomacromolecules. The key point is to introduce an element of asymmetry into the non-amide oligomers and to make them exhibit the expected structures. Only under these conditions can the artificial scaffolds locate their substituents in a similar orientation to the native peptide secondary structures.

The first class of non-amide oligomers has an asymmetric centre axis to mimic the overall backbones in a $\alpha$-helix

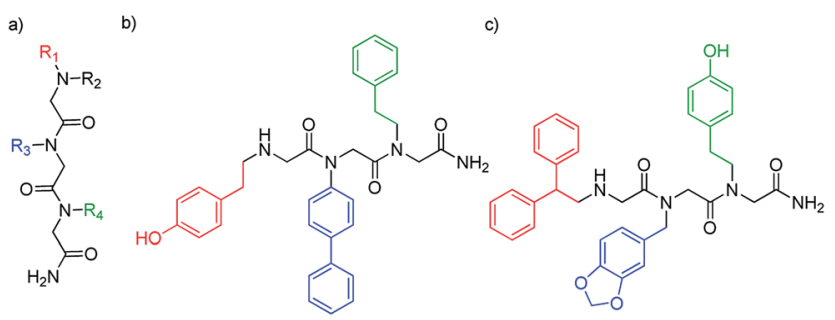

Fig. 9 Peptoids as peptide mimics for the purpose of PPI: (a) general structure of $\alpha$-peptoid; (b) and (c) structural examples of peptoids serving as GPCR binders with nanomolar binding constants. structure, guided by information on the protein structureactivity relationship. The substituent groups are arranged in a rotating manner, as analogs to amino acid residues, which originates from steric effects (Fig. 10).

\subsection{Oligophenyl scaffold and its derivatives}

Oligophenyl scaffold and its derivatives are the first class of molecules with structural interest. ${ }^{135}$ The sequential aromatic rings linked by a single bond are not in the same molecular plane, giving the essential element of asymmetry. ${ }^{136}$ Hamilton et $a l .{ }^{137}$ first made use of the rigid framework resulting from $o$ substituted terphenyl as an $\alpha$-helix mimic (Fig. 11a). In these structures, the distance between two substituent groups localized on two adjacent phenyl groups is 5-6 $\mathrm{A}$, which mimics the $i$, $i+4$, and $i+7$ side chains along a helix. This class of peptidomimetics has been the most successful in the search for PPI inhibitors or antagonists. Bcl-xL is an anti-apoptotic protein overexpressed in some cancer cell lines, which protects the tumour cells from dying even under apoptotic signal conditions. The following two examples dealt with this protein. Hamilton's group developed several terphenyl derivatives to mimic the $\alpha$-helix of Bak-protein to bind with Bcl-xL, acting as potential Bcl-xL antagonists. ${ }^{138}$ NMR data showed an expected binding model with a binding constant $K_{\mathrm{D}}$ in the range of $\mu \mathrm{M}$ to $\mathrm{nM}$, in agreement with the predicted docking result. After that work, the same group further established a terphenyl derivative library based on the mimicking of the $\alpha$-helix Bak-protein BH3 domain. ${ }^{139}$ In vivo experiments in the embryonic kidney $293 \mathrm{~T}$ cell line showed the interruption of the binding between two protein moieties in the presence of certain secondary structural mimics. The same design principle has also been applied to study inhibitors for the p53/HDM2 interaction, the inhibition of which is of great importance for anticancer therapy. Hamilton and coworkers further established a terphenyl candidate library via multiple Suzuki coupling reactions. Through substitution group screening, terphenyl derivatives were found that mimicked the peptide $15-31$ of p53 folding as an $\alpha$-helix. The NMR mapping results showed similar interaction modes to those of the native peptide at the binding pockets of F19 $(i)$, W23 $(i+4)$, and L26 $(i+7)$ on HDM2, with high affinities. ${ }^{\mathbf{1 4 0}}$

An enaminone structure was incorporated into the benzene backbone to overcome the difficulty in synthesis as well as its low water solubility (Fig. 11b and c). Because of the special

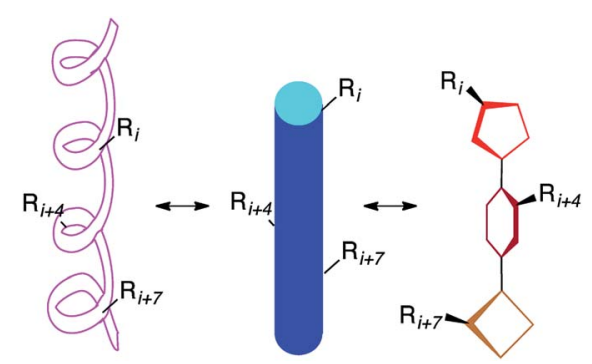

Fig. 10 Scheme for the design principle for a straight stick scaffold with rotating arranged twigs as a helix mimic. 


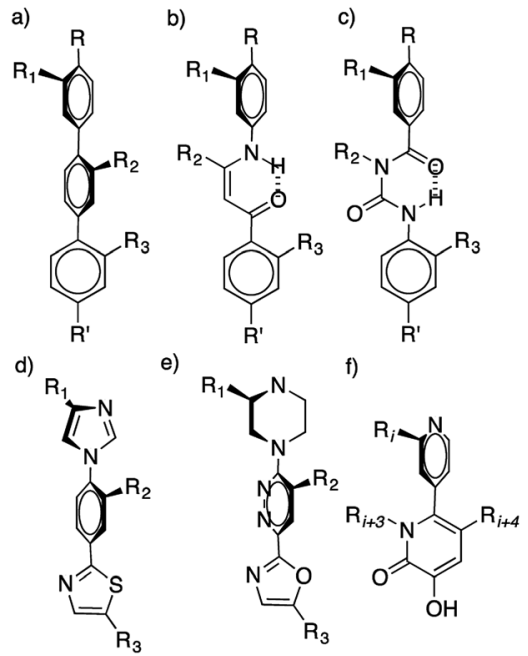

Fig. 11 Oligophenyl scaffold and its derivatives as helix mimics. (a-f) Oligophenyl scaffold and its derivatives, aiming to show the possible usages of diverse aromatic ring structures.

intramolecular hydrogen bonding models, these compounds ${ }^{141}$ are still shown to have the capacity to mimic the $i, i+4$, and $i+7$ side chains along a helix. Through substituent group optimization, these structures ${ }^{142}$ can also bind successfully to the hydrophobic pocket of Bcl-xL with a similar pattern to Bakprotein. Another alternative design comes from the replacement of the benzene ring with other heteroatom-containing rings, including imidazole, thiazole, oxazole, and piperazine (Fig. 11d and e).

In 2007, Hamilton and coworkers made some improvements to the design principle. Through the sophisticated calculation of the relative positions in space, they verified that a 2,6,3'trisubstituted biaryl scaffold would mimic not only $i$ and $i+4$ but also $i+3$ position at the same time (Fig. 11f). ${ }^{143}$ After a careful optimization of substituent groups, the newly generated structures could bind to the ligand-binding domain of the estrogen receptor to inhibit the protein receptor interacting with its native ligand, and thus regulate downstream effects.

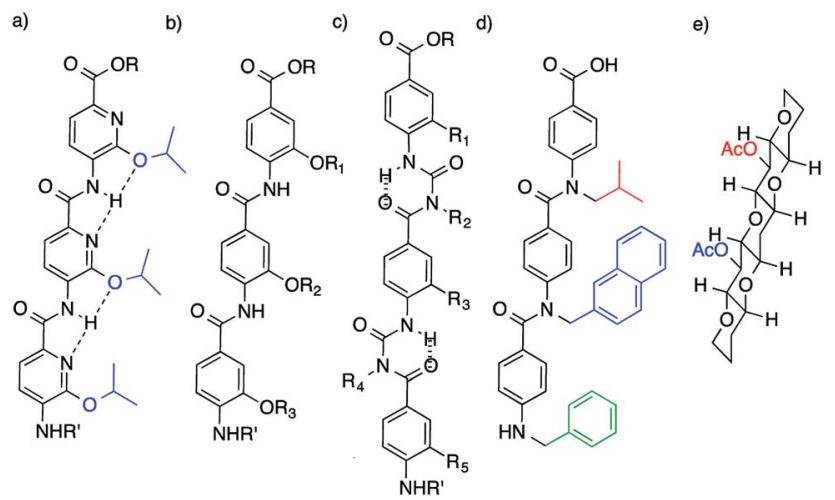

Fig. 12 (a) An example of oligobenzamide scaffold (ref. 128), (b-d) different oligobenzamide scaffold derivatives as helix mimics (ref. 140). (e) An example of polycyclic ether (ref. 137).
One disadvantage of this mimic group is its poor water solubility, which can be improved using the oligobenzamide family.

Peptide-nucleic acid interactions (PNIs) are another group of important inter-macromolecular interactions, having similar properties and models to PPIs. Therefore, terphenylene derivatives ${ }^{134}$ as peptide secondary structure mimics, can also be applied to regulate PNIs.

\subsection{Oligobenzamide scaffold and its derivatives}

Another sub-category of compounds based on non-amide oligomers is compounds with different linkages between the aromatic rings, from a single and rotatable bond to some more complicated spacers. ${ }^{144}$ Besides the oligo- $p$-amino picolinic acid (Fig. 12a), the most widely used groups of molecular units are trisbenzamide derivatives (Fig. 12b-d). Three alkoxyl substitution groups can also be used to mimic the $i, i+4$, and $i+7$ side chains of a native helix structure. The synthesis and characterization of these small molecules have been studied, ${ }^{145}$ and some of them have been applied to protein-protein interaction inhibition. The distances between the oligomer units are not absolutely the same compared with each pitch of the screw in native $\alpha$-helical structures. It is worth considering that the accumulation of error in the overall shape might be a problem in the mimicking of longer helixes. The incorporation of oxygen atoms can also increase the aqueous solubility of compounds from this group. ${ }^{146}$

Based on similar design principles, Oguri and collaborators $^{147}$ designed and synthesized a polycyclic ether as the backbone scaffold (Fig. 12e). These foldamers, inspired by polycyclic ether marine toxins, can mimic the position of $i, i+3$, $i+4, i+7$, and $i+8$. Novel peptidomimetics with structures belonging to this group are continually being developed, such as oligooxopiperazine based on computer-aided rational design, targeting diverse PPIs. ${ }^{148,149}$ These mimics may also be candidates for the inhibition of protein-protein interactions. By introducing chemical handles onto these scaffolds, bioorthogonal reactions can be applied for the purposes of modification or functionalization, which may further modulate the inhibition effects. ${ }^{150}$ Using this design, Wilson and coworkers ${ }^{151}$ further developed a cross-linked dimer strategy as a "multivalent mimic of helix" with increased affinity, by using intermolecular click reactions on the handles.

\section{Conclusion and outlook}

The study of protein-protein interactions has become an important topic due to their key roles in cellular processes and the efficacy of molecules as drugs. An increasing number of chemical strategies have been developed to create protein/ peptide secondary structural mimics that target specific protein-protein interactions. ${ }^{152}$ The versatile, robust, and easily controllable chemical structures and the fine tuning of physical properties endow these peptidomimetics with the potential for high binding affinity and specificity. ${ }^{153}$ In this review, we divided the existing peptide mimics into three major groups based on their structural diversities, and briefly discussed their 
design, synthesis and their applications in the modulation of PPIs.

One of the biggest goals faced in the field is to create more peptide secondary mimics with diverse novel chemical structures. ${ }^{154}$ All categories of current peptide mimics are based on repeating structure units, which can exhibit a rotation structure to mimic helices. ${ }^{155}$ The possibilities of structural design for the purpose of mimicking are theoretically unlimited, and thus molecular designs could number far more than those discussed above. ${ }^{156}$ Interestingly, small molecules can also serve as helix mimics, such as the 2,6,9-tri-substituted purine introduced by Fletcher et $a l .{ }^{157}$ At the same time, the combination of physical chemistry analysis and chemical design can predict better mimetic structures. ${ }^{158}$ If we think out of the box, these helices can be regarded as incomplete and unstable barrels with hollow chambers. Thus, non-repeating molecules may also be able to play a scaffold role as an entire barrel. ${ }^{159}$ Besides attempts to mimic $\alpha$-helices, $\beta$-strand/sheets and turns, loops are also an important but challenging task, which has not been fully emphasized.

Another important goal is to make use of peptidomimetics for screening and to search for leads for medical applications. ${ }^{\mathbf{1 6 0}}$ Advances have been made towards the design and synthesis of diverse oligomer foldamers for those purposes, ${ }^{\mathbf{1 6 1}}$ as well as building mimic libraries for targeting PPIs. ${ }^{162}$ Compared with the traditional screening processes of small molecular or peptide inhibitors, ${ }^{163}$ some basic facilities still need to be fully established for both rational design and high-throughput screening of peptidomimetics. ${ }^{\mathbf{1 6 4}}$ We expect that more and more peptide mimics based on rational design may be applied as new chemical tools and potential clinical therapeutics in the near future. ${ }^{165}$

\section{Acknowledgements}

The authors want to thank Tian Qiu, Xinlei Sheng and Geng Deng at Tsinghua University, Erol Can Vatansever from Texas A\&M University, and Dr Reka Daniel-Weiner at Princeton Neuron Science Institution for their discussions or suggestions. This work was funded in part by the National Natural Science Foundation of China (grant number 21402206) and the Natural Science Foundation of Anhui Province (1508085QB30).

\section{Notes and references}

1 S. Roy, P. Ghosh, N. Sekhar Roy, A. Mazumder, K. Roy, A. Kumar Manna, S. Mallick and I. Ahmed, Curr. Chem. Biol., 2012, 6, 145-163.

2 J. F. Rual, K. Venkatesan, T. Hao, T. Hirozane-Kishikawa, A. Dricot, N. Li, G. F. Berriz, F. D. Gibbons, M. Dreze and N. Ayivi-Guedehoussou, Nature, 2005, 437, 1173-1178.

3 S. Fletcher and A. D. Hamilton, Curr. Opin. Chem. Biol., 2005, 9, 632-638.

4 H. D. Ou, A. P. May and C. C. O'Shea, Wiley Interdiscip. Rev.: Syst. Biol. Med., 2011, 3, 48-73.

5 J. A. Wells and C. L. McClendon, Nature, 2007, 450, 10011009.
6 L. L. Conte, C. Chothia and J. Janin, J. Mol. Biol., 1999, 285, 2177-2198.

7 A. M. De Vos, M. Ultsch and A. A. Kossiakoff, Science, 1992, 255, 306-312.

8 M. R. Arkin and J. A. Wells, Nat. Rev. Drug Discovery, 2004, 3, 301-317.

9 E. J. Sundberg and R. A. Mariuzza, Structure, 2000, 8, R137R142.

10 I. Luque and E. Freire, Proteins: Struct., Funct., Genet., 2000, 41, 63-71.

11 S. J. Teague, Nat. Rev. Drug Discovery, 2003, 2, 527-541.

12 Y. Aye, E. J. Brignole, M. J. C. Long, J. Chittuluru, C. L. Drennan, F. J. Asturias and J. Stubbe, Chem. Biol., 2012, 19, 799-805.

13 T. Clackson and J. A. Wells, Science, 1995, 267, 383-386. 14 A. A. Bogan and K. S. Thorn, J. Mol. Biol., 1998, 280, 1-9. 15 J. A. Robinson, Curr. Opin. Chem. Biol., 2011, 15, 379-386. 16 K. M. Zak, R. Kitel, S. Przetocka, P. Golik, K. Guzik, B. Musielak, A. Dömling, G. Dubin and T. A. Holak, Structure, 2015, 23, 2341-2348.

17 A. Belle, A. Tanay, L. Bitincka, R. Shamir and E. K. O'Shea, Proc. Natl. Acad. Sci. U. S. A., 2006, 103, 13004-13009.

18 J. C. Egrie and J. K. Browne, Nephrol., Dial., Transplant., 2001, 16, 3-13.

19 G. G. Kochendoerfer, S.-Y. Chen, F. Mao, S. Cressman, S. Traviglia, H. Shao, C. L. Hunter, D. W. Low, E. N. Cagle and M. Carnevali, Science, 2003, 299, 884-887.

20 J. Li, Y. Li, Q. He, Y. Li, H. Li and L. Liu, Org. Biomol. Chem., 2014, 12, 5435-5441.

21 R. K. McGinty, J. Kim, C. Chatterjee, R. G. Roeder and T. W. Muir, Nature, 2008, 453, 812-816.

22 R. Okamoto, K. Mandal, M. Ling, A. D. Luster, Y. Kajihara and S. B. Kent, Angew. Chem., Int. Ed., 2014, 53, 5188-5193.

23 C. G. Willett, Y. Boucher, E. Di Tomaso, D. G. Duda, L. L. Munn, R. T. Tong, D. C. Chung, D. V. Sahani, S. P. Kalva and S. V. Kozin, Nat. Med., 2004, 10, 145-147.

24 J. D. Wolchok, H. Kluger, M. K. Callahan, M. A. Postow, N. A. Rizvi, A. M. Lesokhin, N. H. Segal, C. E. Ariyan, R.-A. Gordon and K. Reed, N. Engl. J. Med., 2013, 369, 122-133.

25 C. Zhang, Q. Shen, B. Tang and L. Lai, Angew. Chem., Int. Ed., 2013, 125, 11265-11268.

26 K. Nord, E. Gunneriusson, J. Ringdahl, S. Ståhl, M. Uhlén and P.-Å. Nygren, Nat. Biotechnol., 1996, 15, 772-777.

27 H. N. Chang, B. Y. Liu, Y. K. Qi, Y. Zhou, Y. P. Chen, K. M. Pan, W. W. Li, X. M. Zhou, W. W. Ma, C. Y. Fu and L. Liu, Angew. Chem., Int. Ed., 2015, 127, 11926-11930.

28 L. Liu and Q. X. Guo, Chem. Rev., 2001, 101, 673-695.

29 L. D. Walensky, A. L. Kung, I. Escher, T. J. Malia, S. Barbuto, R. D. Wright, G. Wagner, G. L. Verdine and S. J. Korsmeyer, Science, 2004, 305, 1466-1470.

30 N. C. Wrighton, F. X. Farrell, R. Chang, A. K. Kashyap, F. P. Barbone, L. S. Mulcahy, D. L. Johnson, R. W. Barrett, L. K. Jolliffe and W. J. Dower, Science, 1996, 273, 458-464.

31 L. D. Walensky and G. H. Bird, J. Med. Chem., 2014, 57, 6275-6288. 
32 P. S. Kutchukian, J. S. Yang, G. L. Verdine and E. I. Shakhnovich, J. Am. Chem. Soc., 2009, 131, 4622-4627.

33 Y.-W. Kim, T. N. Grossmann and G. L. Verdine, Nat. Protoc., 2011, 6, 761-771.

34 Y. H. Lau, P. de Andrade, N. Sköld, G. J. McKenzie, A. R. Venkitaraman, C. Verma, D. P. Lane and D. R. Spring, Org. Biomol. Chem., 2014, 12, 4074-4077.

35 H. K. Cui, Y. Guo, Y. He, F. L. Wang, H. N. Chang, Y. J. Wang, F. M. Wu, C. L. Tian and L. Liu, Angew. Chem., Int. Ed., 2013, 52, 9558-9562.

36 Y. Guo, D. M. Sun, F. L. Wang, Y. He, L. Liu and C. L. Tian, Angew. Chem., Int. Ed., 2015, 54, 14276-14281.

37 L. D. Walensky and G. H. Bird, J. Med. Chem., 2014, 57, 6275-6288.

38 L. D. Walensky, K. Pitter, J. Morash, K. J. Oh, S. Barbuto, J. Fisher, E. Smith, G. L. Verdine and S. J. Korsmeyer, Mol. Cell, 2006, 24, 199-210.

39 H.-K. Cui, J. Qing, Y. Guo, Y.-J. Wang, L.-J. Cui, T.-H. He, L. Zhang and L. Liu, Bioorg. Med. Chem., 2013, 21, 35473554.

40 H.-K. Cui, B. Zhao, Y. Li, Y. Guo, H. Hu, L. Liu and Y.-G. Chen, Cell Res., 2013, 23, 581-584.

41 G. L. Verdine and G. J. Hilinski, Drug Discovery Today: Technol., 2012, 9, e41-e47.

42 O. Khakshoor and J. S. Nowick, Org. Lett., 2009, 11, 30003003.

43 M. L. Tan, P. F. M. Choong and C. R. Dass, Peptides, 2010, 31, 184-193.

44 A. Sood and R. Panchagnula, Chem. Rev., 2001, 101, 32753304.

45 J. A. Robinson, Acc. Chem. Res., 2008, 41, 1278-1288.

46 J.-S. Zheng, S. Tang, Y.-K. Qi, Z.-P. Wang and L. Liu, Nat. Protoc., 2013, 8, 2483-2495.

47 J.-S. Zheng, M. Yu, Y.-K. Qi, S. Tang, F. Shen, Z.-P. Wang, L. Xiao, L. Zhang, C.-L. Tian and L. Liu, J. Am. Chem. Soc., 2014, 136, 3695-3704.

48 X. Chen, S. Tang, J.-S. Zheng, R. Zhao, Z.-P. Wang, W. Shao, H.-N. Chang, J.-Y. Cheng, H. Zhao and L. Liu, Nat. Commun., 2015, 6, 1-9.

49 S. Tang, Y.-Y. Si, Z.-P. Wang, K.-R. Mei, X. Chen, J.-Y. Cheng, J.-S. Zheng and L. Liu, Angew. Chem., Int. Ed., 2015, 127, 5805-5809.

50 J.-M. Kee, R. C. Oslund, D. H. Perlman and T. W. Muir, Nat. Chem. Biol., 2013, 9, 416-421.

51 C. Chatterjee, R. K. McGinty, B. Fierz and T. W. Muir, Nat. Chem. Biol., 2010, 6, 267-269.

52 Y. C. Huang, Y. M. Li, Y. Chen, M. Pan, Y. T. Li, L. Yu, Q. X. Guo and L. Liu, Angew. Chem., Int. Ed., 2013, 52, 4858-4862.

53 Y. M. Li, Y. T. Li, M. Pan, X. Q. Kong, Y. C. Huang, Z. Y. Hong and L. Liu, Angew. Chem., Int. Ed., 2014, 53, 2198-2202.

54 Y.-S. Wang, X. Fang, A. L. Wallace, B. Wu and W. R. Liu, J. Am. Chem. Soc., 2012, 134, 2950-2953.

55 W. Wan, Y. Huang, Z. Wang, W. K. Russell, P. J. Pai, D. H. Russell and W. R. Liu, Angew. Chem., Int. Ed., 2010, 49, 3211-3214.
56 Z.-P. A. Wang, C.-L. Tian and J.-S. Zheng, RSC Adv., 2015, 5, 107192-107199.

57 Z.-P. Wang, Y.-H. Wang, G.-C. Chu, J. Shi and Y.-M. Li, Curr. Org. Synth., 2015, 12, 150-162.

58 G. M. Fang, Y. M. Li, F. Shen, Y. C. Huang, J. B. Li, Y. Lin, H. K. Cui and L. Liu, Angew. Chem., Int. Ed., 2011, 50, 7645-7649.

59 G. M. Fang, J. X. Wang and L. Liu, Angew. Chem., Int. Ed., 2012, 51, 10347-10350.

60 J. X. Wang, G. M. Fang, Y. He, D. L. Qu, M. Yu, Z. Y. Hong and L. Liu, Angew. Chem., Int. Ed., 2015, 127, 2222-2226.

61 Y. Huang and L. Liu, Sci. China: Chem., 2015, 58, 1779-1781.

62 M. Martín-Martínez, N. De la Figuera, M. LaTorre, M. T. García-López, E. Cenarruzabeitia, J. Del Río and R. González-Muñiz, J. Med. Chem., 2005, 48, 7667-7674.

63 K. D. Stigers, M. J. Soth and J. S. Nowick, Curr. Opin. Chem. Biol., 1999, 3, 714-723.

64 K. Y. Tsang, H. Diaz, N. Graciani and J. W. Kelly, J. Am. Chem. Soc., 1994, 116, 3988-4005.

65 M. J. Soth and J. S. Nowick, J. Org. Chem., 1999, 64, 276-281.

66 L. Halab, F. Gosselin and W. D. Lubell, Biopolymers, 2000, 55, 101-122.

67 A. Khashper and W. D. Lubell, Org. Biomol. Chem., 2014, 12, 5052-5070.

68 L. Halab, J. A. J. Becker, Z. Darula, D. Tourwe, B. L. Kieffer, F. Simonin and W. D. Lubell, J. Med. Chem., 2002, 45, 53535357.

69 G. M. Grotenbreg, M. S. M. Timmer, A. L. Llamas-Saiz, M. Verdoes, G. A. van der Marel, M. J. van Raaij, H. S. Overkleeft and M. Overhand, J. Am. Chem. Soc., 2004, 126, 3444-3446.

$70 \mathrm{H}$. Van de Langemheen, M. van Hoeke, H. Q. van Ufford, J. Kruijtzer and R. Liskamp, Org. Biomol. Chem., 2014, 12, 4471-4478.

71 J. M. Smith, N. C. Hill, P. J. Krasniak and R. Fasan, Org. Biomol. Chem., 2014, 12, 1135-1142.

72 D. Ranganathan, V. Haridas, S. Kurur, A. Thomas, K. P. Madhusudanan, R. Nagaraj, A. C. Kunwar, A. V. S. Sarma and I. L. Karle, J. Am. Chem. Soc., 1998, 120, 8448-8460.

73 I. G. Jones, W. Jones and M. North, J. Org. Chem., 1998, 63, 1505-1513.

74 R. De Wachter, L. Brans, S. Ballet, I. Van den Eynde, D. Feytens, A. Keresztes, G. Toth, Z. Urbanczyk-Lipkowska and D. Tourwé, Tetrahedron, 2009, 65, 2266-2278.

75 A. 1. A. Dörr and W. D. Lubell, Org. Lett., 2015, 17, 35923595.

76 R. V. Nair, A. S. Kotmale, S. A. Dhokale, R. L. Gawade, V. G. Puranik, P. R. Rajamohanan and G. J. Sanjayan, Org. Biomol. Chem., 2014, 12, 774-782.

77 K. M. Makwana and R. Mahalakshmi, Org. Biomol. Chem., 2014, 12, 2053-2061.

78 J. S. Nowick and J. O. Brower, J. Am. Chem. Soc., 2003, 125, 876-877.

79 R. R. Gardner, G. B. Liang and S. H. Gellman, J. Am. Chem. Soc., 1995, 117, 3280-3281. 
80 K. D. Stigers, M. J. Soth and J. S. Nowick, Curr. Opin. Chem. Biol., 1999, 3, 714-723.

81 R. De Wachter, C. de Graaf, A. Keresztes, B. Vandormael, S. Ballet, G. Tóth, D. Rognan and D. Tourwé, J. Med. Chem., 2011, 54, 6538-6547.

82 D. Núñez-Villanueva, M. Á. Bonache, L. Infantes, M. T. García-López, M. Martín-Martínez and R. GonzálezMuñiz, J. Org. Chem., 2011, 76, 6592-6603.

83 D. S. Pedersen and A. Abell, Eur. J. Org. Chem., 2011, 2011, 2399-2411.

84 H. C. Kolb, M. G. Finn and K. B. Sharpless, Angew. Chem., Int. Ed., 2001, 40, 2004-2021.

85 C. W. Tornoe, C. Christensen and M. Meldal, J. Org. Chem., 2002, 67, 3057-3064.

86 L. Zhang, X. G. Chen, P. Xue, H. H. Y. Sun, I. D. Williams, K. B. Sharpless, V. V. Fokin and G. C. Jia, J. Am. Chem. Soc., 2005, 127, 15998-15999.

87 B. C. Boren, S. Narayan, L. K. Rasmussen, L. Zhang, H. T. Zhao, Z. Y. Lin, G. C. Jia and V. V. Fokin, J. Am. Chem. Soc., 2008, 130, 8923-8930.

88 W. S. Horne, C. A. Olsen, J. M. Beierle, A. Montero and M. R. Ghadiri, Angew. Chem., Int. Ed., 2009, 48, 4718-4724.

89 J. M. Beierle, W. S. Horne, J. H. van Maarseveen, B. Waser, J. C. Reubi and M. R. Ghadiri, Angew. Chem., Int. Ed., 2009, 48, 4725-4729.

90 P. Wipf, T. C. Henninger and S. J. Geib, J. Org. Chem., 1998, 63, 6088-6089.

91 M. McLaughlin, R. Yazaki, T. C. Fessard and E. M. Carreira, Org. Lett., 2014, 16, 4070-4073.

92 D. J. Hill, M. J. Mio, R. B. Prince, T. S. Hughes and J. S. Moore, Chem. Rev., 2001, 101, 3893-4012.

93 C. Gennari, B. Salom, D. Potenza and A. Williams, Angew. Chem., Int. Ed., 1994, 33, 2067-2069.

94 S. H. Gellman, Acc. Chem. Res., 1998, 31, 173-180.

95 C. Baldauf, R. Günther and H.-J. Hofmann, J. Org. Chem., 2004, 69, 6214-6220.

96 G. N. Roviello, S. Di Gaetano, D. Capasso, S. Franco, C. Crescenzo, E. M. Bucci and C. Pedone, J. Med. Chem., 2011, 54, 2095-2101.

97 S. C. R. Lummis, D. L. Beene, L. W. Lee, H. A. Lester, R. W. Broadhurst and D. A. Dougherty, Nature, 2005, 438, 248-252.

98 T. Kawakami, T. Ishizawa and H. Murakami, J. Am. Chem. Soc., 2013, 135, 12297-12304.

99 H.-J. Lee, J.-W. Song, Y.-S. Choi, H.-M. Park and K.-B. Lee, J. Am. Chem. Soc., 2002, 124, 11881-11893.

100 M. D. Fletcher and M. M. Campbell, Chem. Rev., 1998, 98, 763-796.

101 D. Seebach, P. E. Ciceri, M. Overhand, B. Jaun, D. Rigo, L. Oberer, U. Hommel, R. Amstutz and H. Widmer, Helv. Chim. Acta, 1996, 79, 2043-2066.

102 D. H. Appella, L. A. Christianson, I. L. Karle, D. R. Powell and S. H. Gellman, J. Am. Chem. Soc., 1996, 118, 1307113072.

103 D. H. Appella, L. A. Christianson, I. L. Karle, D. R. Powell and S. H. Gellman, J. Am. Chem. Soc., 1999, 121, 6206-6212.
104 X. Li, Y.-D. Wu and D. Yang, Acc. Chem. Res., 2008, 41, 14281438.

105 X. Li and D. Yang, Chem. Commun., 2006, 3367-3379.

106 D. Yang, J. Qu, B. Li, F.-F. Ng, X.-C. Wang, K.-K. Cheung, D.-P. Wang and Y.-D. Wu, J. Am. Chem. Soc., 1999, 121, 589-590.

107 G. V. M. Sharma, V. Manohar, S. K. Dutta, V. Subash and A. C. Kunwar, J. Org. Chem., 2008, 73, 3689-3698.

108 X. Li, B. Shen, X.-Q. Yao and D. Yang, J. Am. Chem. Soc., 2007, 129, 7264-7265.

109 R. P. Cheng, S. H. Gellman and W. F. DeGrado, Chem. Rev., 2001, 101, 3219-3232.

110 D. de Bont, W. J. Moree and R. M. J. Liskamp, Bioorg. Med. Chem., 1996, 4, 667-672.

111 M. Gude, U. Piarulli, D. Potenza, B. Salom and C. Gennari, Tetrahedron Lett., 1996, 37, 8589-8592.

112 W. J. Moree, G. A. van der Marel and R. J. Liskamp, J. Org. Chem., 1995, 60, 5157-5169.

113 Y. J. Chung, L. A. Christianson, H. E. Stanger, D. R. Powell and S. H. Gellman, J. Am. Chem. Soc., 1998, 120, 1055510556.

114 D. Seebach, S. Abele, K. Gademann and B. Jaun, Angew. Chem., Int. Ed., 1999, 38, 1595-1597.

115 M. Werder, H. Hauser, S. Abele and D. Seebach, Helv. Chim. Acta, 1999, 82, 1774-1783.

116 R. P. Cheng, S. H. Gellman and W. F. DeGrado, Chem. Rev., 2001, 101, 3219-3232.

117 R. J. Simon, R. S. Kania, R. N. Zuckermann, V. D. Huebner, D. A. Jewell, S. Banville, S. Ng, L. Wang, S. Rosenberg, C. K. Marlowe, D. C. Spellmeyer, R. Y. Tan, A. D. Frankel, D. V. Santi, F. E. Cohen and P. A. Bartlett, Proc. Natl. Acad. Sci. U. S. A., 1992, 89, 9367-9371.

118 B. C. Hamper, S. A. Kolodziej, A. M. Scates, R. G. Smith and E. Cortez, J. Org. Chem., 1998, 63, 708-718.

119 K. Klinker and M. Barz, Macromol. Rapid Commun., 2015, 36, 1943-1957.

120 C. W. Wu, T. J. Sanborn, R. N. Zuckermann and A. E. Barron, J. Am. Chem. Soc., 2001, 123, 2958-2963.

121 C. W. Wu, K. Kirshenbaum, T. J. Sanborn, J. A. Patch, K. Huang, K. A. Dill, R. N. Zuckermann and A. E. Barron, J. Am. Chem. Soc., 2003, 125, 13525-13530.

122 S. B. Y. Shin, B. Yoo, L. Todaro and K. Kirshenbaum, Biopolymers, 2007, 88, 636.

123 Z. Wang, X. Ding, S. Li, J. Shi and Y. Li, RSC Adv., 2014, 4, 7235-7245.

124 R. N. Zuckermann, J. M. Kerr, S. B. H. Kent and W. H. Moos, J. Am. Chem. Soc., 1992, 114, 10646-10647.

125 A. S. Culf and R. J. Ouellette, Molecules, 2010, 15, 52825335.

126 L. Jia, H. L. Sun, J. T. Shay, A. M. Allgeier and S. D. Hanton, J. Am. Chem. Soc., 2002, 124, 7282-7283.

127 C. A. Olsen, Biopolymers, 2011, 96, 561-566.

128 R. N. Zuckermann, E. J. Martin, D. C. Spellmeyer, G. B. Stauber, K. R. Shoemaker, J. M. Kerr, G. M. Figliozzi, D. A. Goff, M. A. Siani, R. J. Simon, S. C. Banville, E. G. Brown, L. Wang, L. S. Richter and W. H. Moos, J. Med. Chem., 1994, 37, 2678-2685. 
129 D. G. Udugamasooriya, S. P. Dineen, R. A. Brekken and T. Kodadek, J. Am. Chem. Soc., 2008, 130, 5744-5752.

130 M. M. Reddy, R. Wilson, J. Wilson, S. Connell, A. Gocke, L. Hynan, D. German and T. Kodadek, Cell, 2011, 144, 132-142.

131 N. P. Chongsiriwatana, J. A. Patch, A. M. Czyzewski, M. T. Dohm, A. Ivankin, D. Gidalevitz, R. N. Zuckermann and A. E. Barron, Proc. Natl. Acad. Sci. U. S. A., 2008, 105, 2794-2799.

132 N. J. Brown, J. Johansson and A. E. Barron, Acc. Chem. Res., 2008, 41, 1409-1417.

133 R. N. Zuckermann, Pept. Sci., 2011, 96, 545-555.

134 M. Wetzler and A. E. Barron, Biopolymers, 2011, 96, 556560.

135 M. J. Adler and A. D. Hamilton, J. Org. Chem., 2011, 76, 7040-7047.

136 M. K. Jayatunga, S. Thompson and A. D. Hamilton, Bioorg. Med. Chem. Lett., 2014, 24, 717-724.

137 J. T. Ernst, J. Becerril, H. S. Park, H. Yin and A. D. Hamilton, Angew. Chem., Int. Ed., 2003, 115, 553-557.

138 O. Kutzki, H. S. Park, J. T. Ernst, B. P. Orner, H. Yin and A. D. Hamilton, J. Am. Chem. Soc., 2002, 124, 11838-11839.

139 H. Yin, G.-i. Lee, K. A. Sedey, O. Kutzki, H. S. Park, B. P. Orner, J. T. Ernst, H.-G. Wang, S. M. Sebti and A. D. Hamilton, J. Am. Chem. Soc., 2005, 127, 10191-10196.

140 H. Yin, G. i. Lee, H. S. Park, G. A. Payne, J. M. Rodriguez, S. M. Sebti and A. D. Hamilton, Angew. Chem., Int. Ed., 2005, 117, 2764-2767.

141 J. M. Rodriguez and A. D. Hamilton, Tetrahedron Lett., 2006, 47, 7443-7446.

142 J. M. Rodriguez, N. T. Ross, W. P. Katt, D. Dhar, G. i. Lee and A. D. Hamilton, ChemMedChem, 2009, 4, 649-656.

143 J. Becerril and A. D. Hamilton, Angew. Chem., Int. Ed., 2007, 119, 4555-4557.

144 M. B. Dewal and S. M. Firestine, Curr. Med. Chem., 2011, 18, 2420-2428.

145 J.-M. Ahn and S.-Y. Han, Tetrahedron Lett., 2007, 48, 35433547.

146 Z. Lim, P. J. Duggan, A. G. Meyer and K. L. Tuck, Org. Biomol. Chem., 2014, 12, 4432-4444.
147 H. Oguri, A. Oomura, S. Tanabe and M. Hirama, Tetrahedron Lett., 2005, 46, 2179-2183.

148 I. Saraogi and A. D. Hamilton, Biochem. Soc. Trans., 2008, 36, 1414-1417.

149 B. B. Lao, K. Drew, D. A. Guarracino, T. F. Brewer, D. W. Heindel, R. Bonneau and P. S. Arora, J. Am. Chem. Soc., 2014, 136, 7877-7888.

150 A. Barnard, K. Long, D. J. Yeo, J. A. Miles, V. Azzarito, G. M. Burslem, P. Prabhakaran, T. A. Edwards and A. J. Wilson, Org. Biomol. Chem., 2014, 12, 6794-6799.

151 A. Barnard, J. A. Miles, G. M. Burslem, A. M. Barker and A. J. Wilson, Org. Biomol. Chem., 2015, 13, 258-264.

152 M. J. Adler, A. G. Jamieson and A. D. Hamilton, in SmallMolecule Inhibitors of Protein-Protein Interactions, Springer, 2010, pp. 1-23.

153 M. Raj, B. N. Bullock and P. S. Arora, Bioorg. Med. Chem., 2013, 21, 4051-4057.

154 E. Jacoby and A. Mozzarelli, Curr. Med. Chem., 2009, 16, 4374-4381.

155 J. A. Robinson, S. DeMarco, F. Gombert, K. Moehle and D. Obrecht, Drug Discovery Today, 2008, 13, 944-951.

156 A. J. Wilson, Chem. Soc. Rev., 2009, 38, 3289-3300.

157 M. Lanning, P. Wilder, H. Bailey, B. Drennen, M. Cavalier, L. Chen, J. Yap, M. Raje and S. Fletcher, Org. Biomol. Chem., 2015, 13, 8642-8646.

158 C. W. Robinson, C. S. Rye, N. E. Chessum and K. Jones, Org. Biomol. Chem., 2015, 13, 7402-7407.

159 P. S. P. Wang, J. B. Nguyen and A. Schepartz, J. Am. Chem. Soc., 2014, 136, 6810-6813.

160 M. Jesus Perez de Vega, M. Martín-Martínez and R. González-Muñiz, Curr. Top. Med. Chem., 2007, 7, 33-62.

161 S. H. Jung, J. Jeon, H. Kim, J. Jaworski and J. H. Jung, J. Am. Chem. Soc., 2014, 136, 6446-6452.

162 L. R. Whitby and D. L. Boger, Acc. Chem. Res., 2012, 45, 1698-1709.

163 K. Nord, E. Gunneriusson, J. Ringdahl, S. Ståhl, M. Uhlén and P.-Å. Nygren, Nat. Biotechnol., 1996, 15, 772-777.

164 B. P. Gray and K. C. Brown, Chem. Rev., 2014, 114, 10201081.

165 M. Eguchi and M. Kahn, Mini-Rev. Med. Chem., 2002, 2, 447-462. 